\title{
PROVOCATIVE AGENTS: AGENT BASE MODELLING SYSTEMS AND THE GLOBAL PRODUCTION OF ARCHITECTURE
}

\author{
PETER RAISBECK \\ Faculty of Architecture, Building and Planning \\ The University of Melbourne \\ Carlton VIC 3010, Australia
}

raisbeck@unimelb.edu.au

\begin{abstract}
Experimental architects are actively pursuing the use of agent based modelling as a way to dynamically simulate behaviour in cities. These efforts appear to mirror the simulations of climate scientists who have also developed dynamic models which are used to predict both global and regional climate change. In climate models it is the earth as a whole, rather than the city, which is viewed from above as a complex, dynamic and total system. In the models of cities developed by architects and urbanists agent based software has given global cities a new and enchanted life of their own. These modelling experiments and simulations have been theorised in architectural discourse as providing a link between the global city and ecological systems. The mix of biological metaphors and concepts, biomorphic forms, cybernetics and networked geometries in agent based architecture work points to the rise and theorization of systems approaches in 1960s architecture. The emergence of agent based software in architecture and urbanism will be situated in relation to its use and potential in ecological informatics, climate models, defense and manufacturing optimization. This will highlight the issues involved in distinguishing between exploratory and exploitative technological innovations. The nature of exploratory innovation is reflected in the desire of architects to visualise the global city as both an organic totality and as a intelligent and complex organism.
\end{abstract}

Keywords: Architecture, Agent based modelling, Systems theory, Global software markets.

\section{Introduction}

Climate researchers at England's Hadley Centre have placed on their website a Java animation depicting the earth's future (Met Office Hadley Centre 'Temperature'). The centre based in England is one of the world's leading centres for climate change research. As the java animation runs, the earth spins and pulsates with colour. This visualisation of rising temperature is derived from the Intergovernmental Panel on Climate Change's (IPCC) mid-range emissions scenario A1B. According to the IPCC, scenario A1 depicts a world in which rapid economic growth fuelled by the use of fossil fuels continues unabated throughout the 21st Century. The swathes of colour on the surface of this overheating earth change from green to a vivid red in 2100. It is not hard to be impressed by the felicity of this animation as the earth spins towards 2100. Patches of colour emerge and inexorably flow across the earth's territories. This is a visualisation of data that has been digitised, sped up and animated to depict in one web applet 
a global view of a dynamic and organic system. This applet is seductive because it gives the impression that this is an authoritative, definitive and entirely natural view of the earth's future. Indeed, for some of us at least, it is comforting because it at least contests the superstitions of the climate change sceptics.

The animation above is an Atmosphere General Circulation Model (AGCM) which is a three dimensional representation of the atmosphere linked to the land and the cryosphere (those places on earth which are frozen). The animation is based on various meteorological datasets compiled by the Hadley Centre over time and these can only be made sense of through a 3 dimensional visual representation. It is easy to be seduced by the felicity of this animation because it gives us a seamless and vivid impression of the earth's future. The animation represents various meteorological datasets gathered from across the land, oceans and the seas and which can only be given life to via a great deal of computing power. This is borne out by the fact that the centre uses the Metrological Offices NEC SX-6 supercomputers and perhaps this is why it is easy to forget that it this is simply a model (Met Office Hadley Centre 'Types'). As a model the applet has all of the limitations, assumptions and imperfections that we come to expect from simulations and forecasts that predict the future. One limitation in these models produced by the Hadley centre is that they only have resolution of a few hundred kilometres an the animation described above represents only one of the IPCC scenarios using a one particular global model (Met Office Hadley Centre 'Types').

AGCMs are related to weather prediction models but because they predict what will happen to the earth in future centuries they employ a coarser grain of detail. The grain of the Hadley applet is $100 \mathrm{kms}$. AGCMs are also applied to the oceans but these models 'treat the ocean as though it were a layer of water of constant depth (typically 50 metres)' (Met Office Hadley Centre 'Types'). At the next scale down sub-global or Regional Scale Climate models (RCMs) are different from the global models because they show terrestrial and marine landscapes at higher levels of resolution, at a round $50 \mathrm{~km}$, and take into account geographic features such as mountains and other topography which are not usually represented in global models. These models are limited to particular areas and run for shorter periods in the order of about 20 years. In contrast, Ocean General Circulation Models (OGCM) are three dimensional visualisations of ocean and sea ice. The centre has also coupled together the above models to produce the aptly named Coupled Atmosphere-Ocean General Circulation Models (AOGCMs) (Met Office Hadley Centre 'Types'). Hadley has also developed Carbon Cycle models which attempt to model information about carbon dioxide in the atmosphere and simulate what the centre describes as 'climate feedbacks'. These models are related to the centre's three-dimensional global atmospheric chemistry model called STOCHEM. STOCHEM models the 'the main agents responsible for the production and destruction of ozone and methane in the lower atmosphere' (Met Office Hadley Centre 'Types').

\section{Modelling Global Cities}

Like the climate scientists who have used advanced computing to model the earth's climate system architects and urbanists have also begun to use computers to model cities as complex systems. As Diana Periton recently observed in her analysis of the work of the French archivist Marcel Poete 'it was in the eighteenth century that the organic body became the dominant metaphor for the city'. (434) Like the earth in the climate simulation the City has throughout the 20th century been theorised as 'an organism in itself' comprising cells which form a 'social aggregate' exhibiting a 'functional unity' or wholeness (425). For Poete, and many other $20^{\text {th }} \mathrm{C}$ urbanists, the city has and continues to be theorised as a living entity which 'develops partly through biological necessity -in order to survive, it takes its sustenance from its environment and propagates itself-but also because it is an intelligent organism, capable of reflection and the exercise of free will' (425).

The architectural and urban diagram has been an important instrument in theorisation of the city as a living entity. As Paul Emmons notes 'the twentieth century has witnessed a new kind of organic schema: the functional network' (441) Architects used diagrams of this network in order for architecture to bridge "between the microcosmos of the body on one hand and the macrocosmos of the world on the other, reflecting organic metaphors from both directions.' (441) For Emmon 'architectural diagrams need to be understood as not merely transparent to facts but as creative constructions built upon the organic metaphors of body-building-cosmos that animate architecture a vital living body' (455). The prospect that this gap can now be bridged by modelling software rather than by diagrams drawn by hand has given rise to new and vibrant visualisations. These new organic schema appear to have overtaken and given a new life and vitalism to the functional network and bubble diagrams of modernists past. Indeed, 
using the new digital tools the evocative two dimensional ideograms and cluster diagrams of the Smithson's and team X, amongst others, can now be given an anatomical presence and made into flesh on our computer screen's (Smithson).

In recent architectural research global cities have begun to be modelled, visualised and likened to ecological systems through the use of agent based modelling. Agent based modelling is a method of computer simulation that treats social agents as objects which can interact with each other based on predetermined rules. This allows for complex behaviour to be simulated in and emerge from an interactive system. Agent based behaviour is dynamic and different to systems that approach or reach a equilibrium. In these experiments agent based software allows cities to be modelled with a new mimetic and functional range of locomotion, adaptation, learning, structural optimisation and pattern formation and perhaps even intelligence. This is best exemplified in the work of Michael Batty from the Centre for Advanced Spatial Analysis at University College London. Batty employs the concept of fractals to span between the macro cosmos of the natural world and the inhabitants of cities because he argues that 'fractals are good first approximations to the spatial structure of cities' (Cities 14). One of Batty's experiments is a 3-D GIS CAD Model which he called Virtual London (Urban 44). Virtual London is a three dimensional geographic information system linked to a large database of spatial information which can be mined and visualised. Like the meteorological data underlying the Hadley models the information in this database can be represented in 3 dimensions. The model is built using a digital terrain model alongside aerial photographs and then given three dimensions through the use of Light Imaging detection and Radar Data (LIDAR) (Urban 45). It is then be populated with different layers of data from other databases. This can include data such as building populations, financial data, and crime rates. Batty used Virtual London to visualise pollution and experimented with the model to see what would happen if sea levels rose 10 metres if the Greenland icecap melted (Urban 46,47).

Batty argues that 'cities in particular and urban development in general emerge from the bottom up and that the spatial order that we see in patterns at more aggregate scales can be explained only in this way' (Cities 6). Drawing on the science of Artificial Neural Networks Batty distinguishes between cellular automata and agents. He argues that the actions of cellular automata can influence other cells which in turn 'generates a spatial order at more global scales' (Cities 6). He goes on to say that 'This is because cellular structures are able to simulate the kinds of dynamics that characterize the growth of cities through spatial diffusion in the manner of epidemics, where activities influence those next to or adjacent to them' (Cities 6,7). In contrast, agents are more complex because unlike cells they are mobile. Using these two components, cellular automata and agents, Batty is able to model, simulate and represent cities. However, as Batty himself cautions this approach is not necessarily intended to be 'applicable to cities and city design. Our focus is largely on experiments with models that provide us with analogies as to how cities develop and evolve. In short, the models provide laboratories for experimentation' (Cities 9).

Batty's experiments suggest an effort to develop an architectural discourse enhanced by software alongside concepts borrowed from the ecological sciences and mathematics. This conjunction allows the gap, in conceptual terms at least, to be bridged between the body, buildings and cities and the macro cosmos of the world. Virtual London, in the computer at least, takes on a life of its own. To enliven a city in this fashion in order to bridge this gap suggests that writing computer code and scripts is now a prerequisite to being considered a fully fledged member of the architectural avant-garde. In research Institutes and architectural academy's there now exists a widespread movement in order to advance this kind of knowledge. For example, at the Architectural Association a software product, ANSYS Multiphysics, is used to simulate wind flows around building envelopes at different times during the year. This tool is described in its product literature as 'The analysis industry's most comprehensive coupled physics tool combining structural, thermal, CFD, acoustic and electromagnetic simulation capabilities in a single solution '(ANSYS). The simulations or models created by this product can be linked to animation software such as MAYA Autodesk's digital image creation and animation tool (Autodesk). Using this software architects can use and write their own programming scripts in order to combine and extend the simulation capabilities of these different software products.

Despite Batty's cautionary note about the application of these methods to cities a number of experimental architects are actively pursuing the use of digital software as a way to model and design cities. A plethora of research initiatives and seminars are now beginning to focus on the use of advanced software to diagram and simulate urban processes. For example, the June 2007 Digital Cities conference in Dessau examined how emerging digital tools are being used to 
both understand and design cities. It brings together some of the leading architectural designers and theorists in the world in relation to digital cities including: Alisa Andrasek of biothing, Gisela Baurmann of amoebe architecture, Alain Chiaradia of Space Syntax, Kas Oosterhius of ONL Architects, Yusuke Obuchi, from the Architectural Association, London Vesna Petresin Robert of rubedo, Jürgen Mayer, J. Jürgen Mayer $\mathrm{H}$. Architects, and Neri Oxman an AA trained architect from the MIT Computation Group in Boston (Dessau). In addition to the obvious connotations of the brand identities of the companies associated with these architects all of these architects appear to be experimenting with, as Neri Oxman of the MIT Design Lab explains: 'attempts to establish new forms of design knowledge and new processes of practice at the interface of design computer science structural engineering biology and ecology (Oxman).' Her work attempts to integrate scientific principles and advances in modern biology engineering and computation within generative processes of design.

\section{Systems Theory}

The mix of biological metaphors and concepts, biomorphic forms cybernetics and networked geometries in agent based modelling work points to the rise and theorization of systems in the architecture of the 1960s. In the 1960s concepts of holistic and open ended systems were also being explored by Team X. For example, Candilis, Josic and Woods textual description of their Bilbao scheme of 1961 could also be a description of the agent based modelling of contemporary practice.

'The systems will have more than the usual three dimensions. They will include a time dimension. The systems will be sufficiently flexible to permit growth and change within themselves throughout the course of their lives. The systems will remain open in both directions i.e. in respect to smaller systems within them as well as in respect to greater systems around them. The systems will present, in their beginning, an even over-all intensity of activity in order not to compromise the future (Sarkis 96).'

In the post war era architects drew and adapted the systems theory approaches which arose out of operational research methodologies developed in WW2 research programs such as radar. A lineage of these approaches can be discerned in the 1960s systems approaches in the work of a number of architectural theorists but notably the mathematician turned architect Christopher Alexander. This lineage appears to have dissapated in the critiques of technoutopia that arose in the late 1960s and 1970s in the work of the Rowe, Tafuri and architects such as the Krier brothers Significantly systems approaches have re-emerged as architects reengaged with network theory and the new software products. For example the quote above mirrors the ways in which contemporary architects have theorised global cities as organismic and complex systems. As Nicholas Weinstock and Nikolas Stathopoplous explain:

'Cities are complex systems. The flow of vehicles and people within a city represents the emergent behaviour of such a systems, produced by large numbers of decisions of the individuals and their interaction with each other and the transport infrastructure of each city. Complex systems are by definition nonlinear and sensitive to initial conditions, so that small changes in such conditions may produce turbulent behaviour at the global scale'(54).

In the 1960s biological concepts converged with advanced construction, functional programming and design, alongside various techniques of systems analysis. As Bertalannfy, the founder of General Systems Theory, was to state in 1968 'If someone were to analyze current notions and fashionable catchwords they would find 'systems' high on the list.(12) The concept has pervaded all fields of science and penetrated into popular thinking, jargon and mass media (12).' In the 1920s Bertalannfy had contrasted the mechanistic approach to biological disciplines and he consequently 'advocated an organismic conception in biology which emphasizes consideration for the organism as a whole or system, and sees the main objective of biological sciences in the discovery of the principles of organization at its various levels (12).' In popular culture and science after the discovery of the DNA as Lillian. E. Kay has noted code 'molecular biology underwent a striking discursive shift: it began to represent itself as a communication science, allied to cybernetics, information theory and computers (463).' For Kay, a historian of science, 'molecular biology reconfigured itself as a (psuedo) information science and represented its objects in terms of communications systems (including linguistics)' (463).

\section{Ecological informatics and the global city}

In the present day the experiments of Batty and other digital architects appear to draw upon the discursive alliances of Ecological Informatics. As Chon and Park assert Ecological Informatics is 
an interdisciplinary field which seeks to understand ecological systems through 'the use of advanced computational technology for elucidating the principles of information processing at and between all levels of ecosytems' (213). As a field of knowledge Ecological Informatics emerged in the discursive ground that lay between neural networks and the ecological sciences (213). Consequently, spatial models utilizing concepts related to cellular automata and agent based systems have been used in the modelling of forest ecosytems, landscape population dynamics, forest fires, insect infestations and fish stocks. As this field has developed it has begun to focus on the 'advanced interpretation of ecosystems exposed to natural and anthropogenic stress (213).

It might seem curious that a bio-mimetic urge is at the heart of digital architecture. However, the concept of agents allows a direct link to be formed between cities as living entities, a notion as suggested above with a long tradition in architectural discourse, ecosystems and the techniques of digital architecture. Indeed the images of city's produced by agent based software shows cities full of capillarized circulation, organic dispersal and nerve-and naturally, network likelike accumulations. In some architectural proposals, materials, forms and even building type such as towers are now beginning to resemble Haeckel's diatoms as popularised by Darcy Thompson. Agent based software allows the populations of global cities and the atmospheric and climatic forces which act upon them to be conceived atomistically as particles. These particles are given life through agent based modelling, generated by virtue of their unplanned and seemingly random interactions, taking on the patterns and characteristic of larger integrated and global systems. Agent based software allows the city to continue to be depicted as 'an organism within itself.' For digital architects, as Neil Leach has written a 'constructive engagement with biological models is providing new insights into all forms of natural phenomena' (38). He has argued that 'self-generating building systems' would enable 'the translation of the architecture of living things into biological architecture'(38). Leach asserts that, 'it is precisely studies of the 'life-force' within nature-from cellular organizations to swarming and flocking behaviors of insect, plant and animal life-that are opening up understandings of how human beings themselves behave'(38).

For Leach this consideration of agents and swarms in digital architecture leads to the idea that 'Constantly mutating, emergent systems are intelligent systems based on interaction, informational feedback loops, pattern recognition and indirect control. They challenge the traditional concept of systems as predetermined mechanisms of control and focus instead on their self-regulating adaptive capacity'(38). For example, Virtual London model can then be linked back to real time data such as air quality monitors. By embedding avatars into these models we can then explore and presumably manipulate the world that has been created. In Batty's words using various agent based models architects can then organise or simulate these cities in order to 'reveal enormous possibilities for innovative and exciting ways in which we might think about design and planning and the management of change. More importantly these parallel worlds open up the design of our cities to a much wider public, as well as transforming the way we might deliver services. Seek information and engage in new kinds of dialogue'(Batty Cities). Leach has recently completed a design studio at Dessau entitled 'softLAB' in which he states grandly the 'This project takes its inspiration from recent scientific research into the programming of nature. From research into DNA and the Genome Project to the exploration of cellular automata, scientists are attempting to understand the coding of the natural universe. This studio attempts to take the principle of coding or scripting and use it as a generative tool for architecture (Soft).'

\section{The global market for agent based modelling}

Despite all of these hopes agent based software is still in 'an early stage of market development'. This market has a number of segments and most agent based modelling software can be classified as open source software and is often freely available and distributed under an open license. But also associated with this market a number of proprietary products such as Agent Sheets, iGEN, AnyLogic and MASS (Swarm) Indeed industry insiders have asserted that 'the majority of users adopting the technology are visionaries who have recognized the long-term potential of agent systems'( Munroe, et al. 345). For this reasons case studies involving the commercial deployment of agent applications are only just emerging. In Europe Euriobios-an integrated software company involved in software development 'from algorithm design through to implementation.'-has specialized in 'business optimization problems.' For example, Euriobios has used agent based solutions have also been used in order to optimize packaging plant operations. More disturbingly, one area in which agent based modelling is being rapidly adopted and which might drive the development of agent 
technologies is in the area of defence. For example, the AOS group founded in Australia in 1997 has 'built a multi-million dollar annual revenue stream through partnerships with a variety of defense related organizations using agents to simulate human behaviour in a range of adverse conditions.'( Munroe et al. 347 )

Another obvious problem for architects is that agent based modelling is only just being applied to geospatial simulations. As Castles and Cook point out this work involves linking Geographic Information Systems with agent based modelling systems. Such models give the impression that buildings and even cities can be intelligent and cybernetically respond to various situations. The Foundation for Intelligent Physical Agents FIPA an organization that promotes agent-based technology and the interoperability of its standards with other technologies.' The purpose of the organization is to develop standards 'for agents and agent-based systems into the wider context of software development. In short, agent technology needs to work and integrate with nonagent technologies' (FIPA).

In this context, it is useful to consider the type of innovations that are being developed by those architects interested in agent based systems. As Tushman and Brenner point out work on innovation theory distinguishes between incremental and exploitative innovations and more radical innovations. Brenner and Tushman argue that innovations are either incremental or radical: 'incremental innovation, characterized by small changes in a technological trajectory, builds on the firms current technical capabilities, while radical innovation fundamentally changes the technological trajectory and associated organizational competencies'(238). As they explain: ' Incremental technological innovations and innovations designed to meet the needs of existing customers are exploitative and build upon existing organisational knowledge. In contrast radical innovations or those for emergent customers or markets are exploratory since they require new knowledge or departures from existing skills'(238). Across these dimensions the use of agent based software is clearly an exploratory innovation rather than exploitative one. This is because these techniques require architects and urbanists to gain new knowledge in software engineering a clear departure from their current technical capabilities. Moroever, the hope that buildings or cities themselves may one day become intelligent and performative bodies or entities is again a exploratory innovation rather than an exploititative one. This is because innovations can be classified by the way they 'affect existing sub systems and/or linking technologies. Modular innovations affect sub-system or component technology, leaving linking mechanisms intact, while architectural innovations involve changes in how subsystems are linked together.'(238) Again given the rhetoric of architects and urbanists in relation to agent based technologies they must be classified as exploratory innovations rather than exploitative ones.

Some of the issues involved in distinguishing developing exploratory and exploitative innovations can be seen in the development of the climate change models. There is an obvious gap between the climate models and the environmental performance of cities. Currently no urban landscapes have been included in global and regional climate models. This is surprising given that urbanization is a key process which transforms land use and its effects on the earths ecosystems. Climate change models are simulated in land models and then coupled with atmosphere models through the interaction or exchange of heat and water. Moreover, urban classifications are not included in any of the major GCM or RCM surface models. This would imply that current GCMs and RCMs are inadequate for simulating the urban modifications to climate. This calls into question the idea that cities might one day be intelligent organisms which can regulate their own environmental performance in relation to the global climate.

Indeed, the effect of cities on climate is only just beginning to be addressed by climate change scientists. Whilst urban regions only constitute approximately half of the lands surface rapid urbanisation in mega cities points to the need to consider the effects of anthropogenic warming on city populations. It is thus important for climate scientist to begin to look at the feedback effects of cities on the earths climate. However, to do this requires developing data and datasets that are not currently available. Climate scientist are only now beginning to consider how satellite data showing processes of urbanisation can be used in the models. Some of the issues that climate scientists have considered in relation to this is the impact of impervious urban surfaces on both hydrology and aldbedo emissivity and the geometry of objects within cities. These factors effect the transport of heat and moisture between cities and the overlying atmosphere. The Hadley centre has also developed a model called PRECIS which has helped to 'generate high-resolution climate change information for as many regions of the world as possible' (Met Office Hadley Centre 'Types') The centre hopes that this model can be available for use by groups in developing countries in order for them to develop there own climate change scenarios. According to the Hadley Centre these studies can be used for impact, vulnerability 
and adaptation studies. Architects and urbanists are yet to link this type of model to their own experiments.

Agent based systems allow architects to visualise global cities as both an organic totalities and as intelligent and complex organisms. Agent based systems are an obvious vehicle to achieve this. But, as suggested above these software technologies are exploratory and from this perspective it may be some time before they become exploitative technologies. In other words, it may take a considerable amount of time for digital architects to develop technologies that are able to link together the necessary technological sub-systems in order for cities themselves to perform in an environmentally intelligent way. In architectural discourse it is reasonable to suggest as Batty does that these urban experiments and models using agent based systems are indeed experiments. They are exploratory attempts by digital architects to explore how cities can be created, analysed and simulated using agent based modelling. This type of software promises the possibility of exploring parallel online cities using mobile agents and avatars in order to plan and forsee the urban spaces of the future. It would perhaps be too cynical to suggest that these endeavours all seem to echo and allude to the architectural and urban possibilities to be found in the online game Second Life. This is not to deny the legitimacy of these architectural experiments in relation to agent based systems. But it does suggest that the imperfections and difficulties underlying the seductive image of the Hadley centre's applet also bedevil the enchanting and dare I say infotainment, agent based images and models created by digital architects. Within the cities of digital architects these avatars and agents are given a poetic and enchanted life of their own. I am concerned that the enchanted life of these cities seems removed in technological distance from an overheating globe on the brink of catastrophe.

\section{References}

ANSYS. 'ANSYS Multiphysics' ANSYS. June 12007

<http://www.ansys.com/products/multiphysics.asp>

Autodesk. 'Autodesk MAYA' Autodesk. June 12007

<http://usa.autodesk.com/adsk/servlet/index?sitelD=123112\&id=7635018>

Batty, Michael. Cities and complexity : understanding cities with cellular automata, agent-based models, and fractals. Cambridge, Mass. : MIT Press, 2005

Batty Michael and Hudson-Smith Andrew. 'Urban Simulacra: London.' Architectural Design 75/6 (2005): 42-47

Benner, Mary J. Tushman, Michael, L. 'Exploitation, exploration and process management the productivity dilemma revisited.' Academy of Management Review 28/2 (2003): 238-256.

Bertalanffy, Ludwig von. General system theory : foundations, development, applications New York : G. Braziller 1968

Carpo, Mario. 'Tempest in a teapot' Log 5 (2005): 99-106.

Chon, Tae-Soo and Park, Young-Seuk. 'Ecological informatics as an advanced interdisciplinary interpretation of ecosystems.' Ecological Informatics 1/3 (2006): 213-217 (November 2006)

Castle, Christian J.E. Crooks, Andrew T. 'Principles and Concepts of Agent Based Modelling for Developing Geospatial Simulations' UCL Working Paper Series Paper 110-Sep 2006 Centre for Advanced Spatial Analysis University College London.

Desssau Institute of Architecture. 'Digital Cities Conference.' Desssau Institute of Architecture. June 1 2007. <http://www.afg.hs-anhalt.de/dia/>

Emmons, Paul. 'Embodying networks: bubble diagrams and the image of modern organicism.' The Journal of Architecture 11/ 4 (September 2006):

The Foundation for Intelligent Physical Agents. June 12007 <http://www.fipa.org/>

Jin Menglin, Shepherd, J. Marshall. 'Inclusion of Urban Landscape in a Climate Model; How can Satellite Data Help.' American Meteorological Society. (2005): 681-689.

Kay, Lily. E. 'How a Genetic Code became an information System.' in A.C. Hughes and T.P.Hughes eds. Systems, Experts and Computers: The Systems Approach in Management and Engineering, Word War II and After. Cambridge, Mass: MIT Press 2003: 463 
Leach, Neil. 'Swarm Tectonics', in Leach, Turnbull, Williams (ed.) Digital Tectonics London: Wiley 2004: 38.

Met Office Hadley Centre. 'Temperature Rise for A1B projection.' Met Office Hadley Centre. Climate change projection. June 12007

<http://www.metoffice.gov.uk/research/hadleycentre/models/modeldata.html>

Met Office Hadley Centre. 'Types of climate models' Met Office Hadley Centre. Types of climate models. June 12007

<http://www.metoffice.gov.uk/research/hadleycentre/models/modeldata.html>

Munroe Steve, Miller Tim, Belecheanu Roxana a., Pechoucek Michal, Mcburney, Peter and Luck, Michael. 'Crossing the agent technology chasm: Lessons, experiences and challenges in commercial applications of agents.' The Knowledge Engineering Review 21/4, (2006): 345392.

Neri Oxman. 'Material Ecology design research.' Neri Oxman. June 12007. $<$ http://www.materialecology.com/>

Periton, Diana. 'Generative history: Marcel Poëte and the city as urban organism' The Journal of Architecture 11/ 4 (September 2006):

Proctor, Robert. 'Architecture from the cell-soul: René Binet and Ernst Haeckel.' The Journal of Architecture 11/ 4 (September 2006):

Rau, Erik. P. 'Technological Systems, Expertise and Policy Making: The British Origins of Operational Research. Technologies of Power: Essay's in Honour of Thomas Park Hughes and Agatha Chipley Hughes ed. Michael Thad Allen and Gabrielle Hecht. The MIT Press Cambridge Massachusetts, London England. 2005?

Sarkis, H. Le Corbusier's Venice Hospital. Munich, London, New York : Prestel Verlag 2001

Smithson, Alison Margaret and Peter. The charged void : urbanism. New York : Monacelli Press 2005.

SwarmWiki. 'Tools for agent based modeling.' June 12007 <http://www.swarm.org/wiki/Tools_for_Agent-Based_Modelling>

Weinstock,Michael and Stathopoulos Nikolaos. 'Advanced simulation in design.' Architectural Design 76/2 (2006): 54-59

'Editorial: Modelling land use change and environmental impact'. Journal of Environmental Management 72, (2004): 1-3. 